\title{
The Effects of Expiratory Muscle Strength Training on Lung Function and Musical Performance in Collegiate Wind Instrumentalists
}

\author{
Natalie Woodberry, Julia Slesinski, Megan Herzog, Miranda Orlando, Jessica \\ St. Clair, \& L. Maureen Dunn * Corresponding Author \\ Hope College, Department of Kinesiology, Holland, MI.
}

\section{ABSTRACT}

Expiratory muscle strength training (EMST) has been associated with increased maximum expiratory pressure (MEP). Because wind instrumentalists depend on sufficient pressure production for optimal musical performance, it is possible that EMST might improve musical performance in this population. The purpose of this study was to determine if 4 weeks of EMST would improve instrumental performance in relation to MEP in collegelevel wind instrumentalists. All participants ( $\mathrm{N}=19)$ were pretested for MEP $\left(\mathrm{inH}_{2} \mathrm{O}\right)$ and musical performance measures of loudness $(\mathrm{dB})$ and duration of play (sec) on various pitches. Participants were then divided into groups matched by MEP, gender, and instrument. The experimental group ( $\mathrm{n}=12)$ trained 4 times/week for 4 weeks at 75\% MEP. Following training, MEP increased significantly in the experimental group (pre: 49.50 \pm 14.41 ; post: $83.17 \pm 22.47 \mathrm{inH}_{2} \mathrm{O}$ ) compared to the control group (pre: $50.29 \pm 7.76$; post: $53.14 \pm 11.89 \mathrm{inH}_{2} \mathrm{O}, \mathrm{p}<0.0001$ ). There were no significant musical performance improvements as measured following training, but results suggest that EMST may be a viable option for instrumental training. Future research might build upon this study design to better assess the effects of EMST on musical performance in wind instrumentalists by considering alternate definitions for musical performance and by assessing specific instruments separately.

Keywords: Maximum expiratory pressure (MEP), musical performance, expiratory strength training (EMST), wind musicians 
Expiratory muscle strength training (EMST) has been shown to improve expiratory muscle function, strength, and endurance (Baker, Davenport \& Sapienza, 2005), as well as to reduce respiratory fatigue (Verges, Lenherr, Haner, Schulz \& Spengler, 2007). The primary expiratory muscles that have shown response to training are the internal intercostals and the abdominals (Powers \& Criswell, 1996). In addition, training has been shown to improve maximum expiratory pressure (MEP, Anand, El-Bashiti \& Sapienza, 2012; Illi, Held, Frank \& Spengler, 2012; Sagdeo \& Khuje, 2012), thus improving cough production, swallow function, and breathing in diseased populations (Anand et al., 2012). Healthy wind instrumentalists also may benefit from increased MEP because they must exhale for long periods of time and manipulate their expiratory pressures in order to optimize tone production (Bouhuys, 1964). Several studies have observed the effect of EMST on MEP in both diseased populations (Anand et al., 2012;Sapienza \& Wheeler, 2006) and in healthy exercisers (Illi, Held, Frank \& Spengler, 2012;Verges et al., 2007), but current knowledge is limited regarding the effect of EMST on the musical performance and lung function of wind instrumentalists. The present study examined whether EMST would improve MEP, and subsequently improve musical performance and/or decrease breathlessness in collegiate wind instrumentalists. Musical performance was operationally defined as the duration and loudness of play at a constant pitch because duration and loudness appear to be related to expiratory pressure (Bouhuys, 1968; Baker et al., 2005).

Changes in MEP have been evaluated in healthy young adults after participation in a 4-week and an 8-week EMST program (Baker et al., 2005). All participants in Baker's study trained 5 times per week, and each training session consisted of 5 sets of 5 breaths at $75 \%$ of maximum MEP. Both groups' mean MEP significantly improved with training, but there was no significant additional MEP improvement during the second 4-week period (Baker et al., 2005). Healthy young adult participants in a different study trained over a 4-week EMST program, with a training frequency of either 5 or 3 days per week (Anand et al., 2012). Results showed that EMST significantly improved MEP in all participants, with no significant differences between groups (Anand et al., 2012). Thus, expiratory muscle strength training on 3 to 5 days per week for 4 weeks has previously been shown to improve MEP in healthy young adults (Anand et al., 2012; Baker et al., 2005).

These gains could be functionally important to wind musicians because maximum expiratory pressure may affect wind music production. Playing a wind instrument taxes the human respiratory system because it requires a large amount of air and pressure (Bouhuys, 1964). Professional wind instrument players have been shown to have a significantly greater vital capacity (VC), total lung capacity (TLC), and volume expired during the first 0.75 seconds of a forced expiration after a maximal inspiration $\left(\mathrm{FEV}_{0.75}\right)$ than a control group of non-instrumentalists (Buohuys, 1964). Wind instrumentalists have also demonstrated greater forced vital capacity (FVC) and expired volume in the first second of 
a forced expiration $\left(\mathrm{FEV}_{1}\right)$ than a control group (Sagdeo \& Khuje, 2012). Although wind instrumentalists appear to have significantly greater lung function than noninstrumentalists (Bouhuys, 1964; Sagdeo \& Khuje, 2012), EMST has been previously shown to increase MEP in high-school wind instrument players by approximately 50\% (Sapienza, Davenport \& Martin, 2002). Therefore, wind instrumentalists with an above-average MEP before training may still be able to further increase MEP with EMST. However, little is known regarding the effect of an increased MEP on musical performance in wind instrumentalists.

Wind instrument players must attain a high degree of voluntary control over their breathing in order to produce sound by regulating the flow of air and pressure through an instrument's vibrating device (Bouhuys, 1964; Faske, 2013). This vibration occurs with expiration (Faske, 2013). During expiration, constant mouth pressure and airflow rate are necessary to sustain a constant pitch and loudness; as pitch and loudness increase, pressure must also increase (Bouhuys, 1968). Therefore, MEP may limit a player's ability to sustain high-pressure requiring (usually loud and high-pitched) tones. In singers, Baker et al. (2005) reported that an increased MEP led to improved vocal performance on loud, long notes. Because MEP may limit wind instrument performance and EMST increases MEP, EMST could translate into improvements in musical performance components of loudness and duration. This may allow instrumentalists to sustain high-pressure-requiring tones over longer durations.

The purpose of this study was to determine the effects of an EMST training program on musical performance, as defined by the duration and loudness at which a college wind musician could play his/her highest and lowest notes while staying in tune. We hypothesized that a 4-week EMST program would increase MEP and reduce breathlessness in collegiate wind instrumentalists, which would lead to improved musical performance as defined by this study.

\section{METHOD}

\section{Participants}

Participants included 20 collegiate (age 18-22 years) wind-instrumentalists. Volunteers were recruited from the orchestra, wind ensemble, and concert band at a private liberal arts college, through emails and in-person recruitment during rehearsals. Exclusion criteria included current smoking, chronic pulmonary disease, asthma, resting blood pressure above $140 / 100 \mathrm{mmHg}$, and occurrence of an upper respiratory tract infection or common cold at any point during the study. All participants completed informed consent and health history forms prior to the pretest. Participants were asked to maintain their current physical activity and musical practice levels throughout the study duration and report any significant changes, defined as increases or decreases in time 
spent on either of these activities by more than 2 hours per week. One participant was excluded after the first week of training due to medical reasons not related to the study. All testing and training was completed in the same location. The time of day for the pre- and post-tests was kept consistent for each participant, and all experimental participants trained in the afternoon. This study was approved by the Human Subjects Review Board at Hope College, Holland, Michigan.

\section{Study Design}

Participants were divided into 2 groups matched by baseline MEP, gender, and instrument. There were 7 males and 5 females in the training group $(n=12)$, and 3 males and 4 females in the control group $(n=7)$. The training group included 1 flute, clarinet, saxophone, bassoon, trumpet, and French horn, as well as 2 oboes, trombones, and tubas. The control group consisted of 1 flute, clarinet, oboe, trumpet, French horn, trombone, and euphonium. Both the training and the control groups completed the pre- and post-testing; additionally, the training group performed a 4-week EMST program.

\section{PROCEDURES}

\section{Familiarization}

Before pretesting, all subjects participated in a preliminary session to familiarize themselves with the equipment used in this study. At this time, resting blood pressure was measured. Each subject was familiarized with the spirometer (Astra 300, SDI Diagnostics, Easton, MA), pressure gauge, and the EMST device (EMST 150, Aspire Products, LLC, Gainesville, FL). Each subject performed 5 trials on each device. The researchers also explained the process for musical performance testing, and the participants performed two practice endurance trials on their instruments, during which they held each of 4 tones for as long as possible while maintaining constant frequency (within \pm 20 cents), as shown by a tuner visible to both the participant and the researcher.

\section{Testing}

There were two stages each of baseline and post-training testing. The first stage was the lung function testing using the pressure gauge and the spirometer. To measure initial maximum expiratory pressure (MEP), each participant wore a nose clip, inhaled to total lung capacity (TLC), placed the pressure gauge mouthpiece in his/her mouth, and expired at maximum force while seated to mimic usual playing position. He/she repeated the process until 3 measures within $5 \%$ of each other were obtained. The greatest of these 3 trials was the recorded MEP. During this period, general lung function was also assessed using a handheld spirometer. Participants wore a nose clip, placed the mouthpiece in their 
mouth, inhaled to TLC, and exhaled as forcefully and as long as possible while in a seated position. The spirometer measured peak expiratory flow (PEF), forced vital capacity (FVC), and forced expiratory volume in 1 second $\left(\mathrm{FEV}_{1}\right)$ over 3 trials. The highest values were recorded.

The functional playing test occurred at least 6 hours after the lung function test for each participant in order to allow sufficient recovery time. Before testing, the participant was allowed 5 minutes to warm up. The participant was instructed to play for as long as possible on each of 4 different tones determined by the participant: the highest note they felt comfortable playing as loudly as possible, the highest comfortably playable note as quietly as possible, then the lowest note they felt comfortable playing as loudly and as quietly as possible. The duration of each note was measured with a stopwatch, and loudness was measured using a hand-held decibel meter. Musicians were instructed to stay within \pm 20 cents on a tuner, which was monitored by both the participant and the researcher. Each tone, in the order of high pitch/high loudness, high pitch/low loudness, low pitch/high loudness, and finally low pitch/low loudness, was performed 3 times, with 1 minute of rest between each trial. Trials were terminated when the participant ran out of breath or when loudness on the decibel reader decreased rapidly by $5 \mathrm{~dB}$ or more.

The handheld decibel meter displayed the decibel level at each moment in time, and thus was not able to calculate the duration of play at each specific decibel level. Therefore, researchers recorded the range of decibel levels from minimum to maximum, and calculated a mean loudness from this range for each trial. Because 3 trials were performed on each tone, the trial associated with the longest duration of play and its corresponding loudness range and mean loudness was used in the statistical analysis.

The subject's rating of perceived breathlessness on the Borg scale (6-20) was assessed at the end of the testing session, after completion of all trials of all tones.

For the post-test sessions the same procedure was used. Participants were tested at the same time of day for the post-testing sessions as the baseline testing, and played the same pitches as in the pretest. Post-testing occurred within 4 days of the final training session.

\section{Training}

Both groups continued with their normal activities throughout the study duration. Additionally, the training group performed 4 weeks of supervised training on 4 days per week using the EMST 150 trainer. Training sessions typically lasted between 15 and 20 minutes; participants performed 5 sets of 5 expiratory breaths at $75 \%$ of the greatest MEP measured during the pretest with 15 seconds between each breath and 1 minute between each set. MEP was reassessed at the beginning of the first training session of each week. Due to scheduling and time constraints, most participants trained in groups of 2-6 people. A few participants trained individually routinely or for make-up sessions. By the third 
week of training, 5 participants reached the maximum resistance of the EMST training device and continued training for the remainder of the study at the maximum of 150 mmHg. At the end of each training session, the researchers assessed participants' enjoyment rating on a 0-10 scale to determine if it might be feasible to add this type of training to regular practice routines in this population.

\section{Statistical Analysis}

A $2 \times 2$ (group by time) repeated measures ANOVA was used to analyze lung function (FVC, FEV1, and PEF), MEP, music performance loudness, and duration of play between groups and over time. Changes in MEP and enjoyment in the experimental group over time were assessed using a one-way repeated measures ANOVA with Bonferroni correction. Differences between successive time points were compared using the within-subjects repeated contrast function. A $2 \times 2 \times 2$ (group [experimental vs control] by type [brass vs. woodwind] by time [pre vs post]) repeated measures ANOVA was used to compare changes in MEP and FVC values between brass players and woodwind players in both groups at pre and post time points. Finally, a two-tailed independent samples t-test was used to compare pre-FVC values between brass and woodwind players. All statistical analyses were performed with SPSS 23.0 statistical package.

\section{RESULTS}

\section{Lung Function: Spirometry}

Forced vital capacity (FVC), forced expiratory volume in one second $\left(\mathrm{FEV}_{1}\right)$, and peak expiratory flow (PEF) were assessed at the pretest and the post-test in both the experimental and control groups. There were no significant differences in the values between the training and the control groups at the pretest. There were no significant changes in $\mathrm{FEV}_{1}$ or PEF over time or between groups ( $\mathrm{p}>0.05$, Table 1$)$. There was a main effect for a decrease in FVC in both groups over time $\left(F(1,15)=5.30, p=0.036, \eta_{p}^{2}=0.26\right.$, Table 1). Although assessment of changes in lung function by instrument type was not a primary objective of this study, it was noted that pre-FVC values for brass instrumentalists were significantly higher $(5.66 \pm 1.66 \mathrm{~L} / \mathrm{min})$ than those of woodwind players $(4.46 \pm 0.95$ L/Min, $t(17)=2.435, p=0.026$ ). However, further analysis (3-way interaction between instrument type by group by time) of FVC did not reveal a main effect for instrument type when post-test data was included $\left(F(1,15)=3.30, p=0.089, \eta_{p}^{2}=0.18\right)$. 
Woodberry et al.

EMST and Musical Performance

Table 1

Lung Function Values: Four Weeks of Expiratory Muscle Strength Training or Control

\begin{tabular}{lcccccr}
\hline & \multicolumn{2}{c}{ FVC $(\mathrm{L} / \mathrm{min})$} & \multicolumn{2}{c}{$\mathrm{FEV}_{1}(\mathrm{~L})$} & \multicolumn{2}{c}{ PEF (L) } \\
\cline { 2 - 7 } & Pre & Post & Pre & Post & Pre & Post \\
\hline Training & $5.3 \pm 1.2$ & $4.98 \pm 1.4^{*}$ & $4.4 \pm 0.9$ & $4.2 \pm 1.1$ & $9.1 \pm 2.1$ & $9.5 \pm 2.2$ \\
Control & $4.8 \pm 1.4$ & $4.4 \pm 1.3^{*}$ & $4.2 \pm 1.2$ & $3.9 \pm 1.1$ & $8.0 \pm 2.7$ & $8.8 \pm 2.6$ \\
\hline
\end{tabular}

Note. Values are means \pm standard deviation for forced vital capacity (FVC), forced expiratory volume in one second $\left(\mathrm{FEV}_{1}\right)$, and peak expiratory flow (PEF). *main effect for time, significantly different from pre-value, $\mathrm{p}<0.05$

\section{Lung Function: Maximum Expiratory Pressure}

Maximum expiratory pressure was measured in both the training and the control groups at the pre- and post-tests. The experimental group MEP was reassessed weekly over the 4-week training period. A significant interaction effect $\left(F(1,17)=26.21, p<0.0001, \eta_{p}^{2}=\right.$ 0.61) showed greater MEP improvement from pretest to post-test in the training group (pre: $49.50 \pm 14.41 \mathrm{inH}_{2} \mathrm{O}$; post: $83.17 \pm 22.47 \mathrm{inH}_{2} \mathrm{O}$ ) compared to the control group (pre: $50.29 \pm 7.76 \mathrm{inH}_{2} \mathrm{O}$; post: $53.14 \pm 11.89 \mathrm{inH}_{2} \mathrm{O}$, Figure 1). In addition, MEP was significantly higher than the pre-value in the training group after 2 weeks of training $(F(1,11)=19.03, p$ $\left.=0.001, \eta_{p}^{2}=0.63\right)$. MEP continued to increase significantly from week 2 to week $3(F(1,11)$ $\left.=10.2, p=0.009, \eta_{p}^{2}=0.48\right)$, and from week 3 to week $4\left(F(1,11)=7.98, p=0.017, \eta_{p}^{2}=\right.$ $0.42)$, but the week 4 MEP was not different than the post-test MEP value $(F(1,11)=0.36, p$ $=0.56, \eta_{p}^{2}=0.03$ ). 


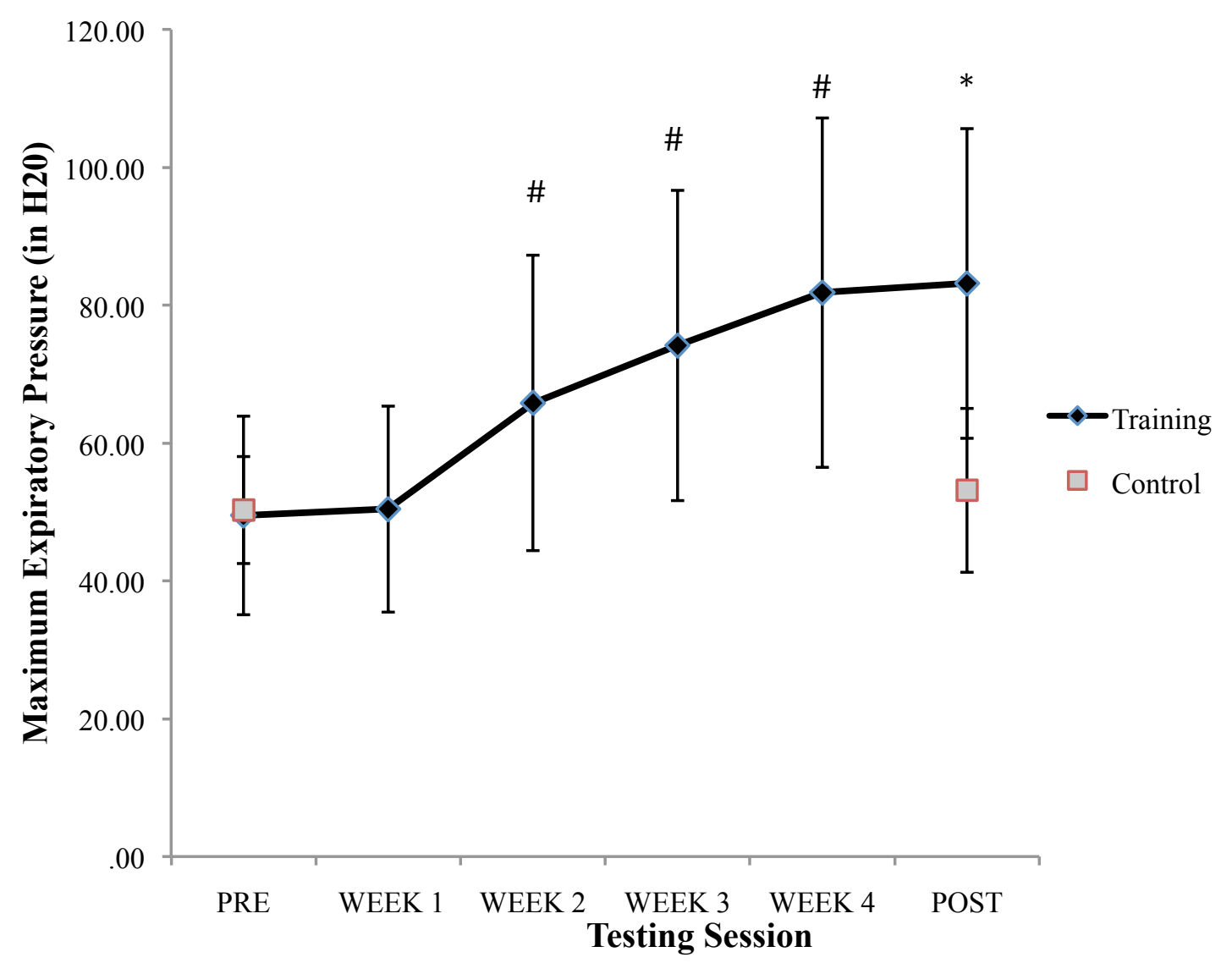

Figure 1. Maximum expiratory pressure before, during (training group only), and following expiratory muscle strength training in both groups. *significant interaction $(\mathrm{p}<0.001)$ between pre and post-test. \#significantly greater than prior week in training group $(\mathrm{p}<0.05)$.

Results also suggested that mean MEP varied depending on the type of instrument (Figure 2a). However, statistical changes in MEP between individual instruments associated with training could not be determined due to the small number of instruments. Interestingly, when instruments were categorized into brass and woodwind, the brass players produced $22.9 \%$ higher MEP at pretest $\left(54.6 \pm 13.01 \mathrm{inH}_{2} \mathrm{O}\right.$ ) compared to the woodwind players $\left(44.44 \pm 8.92 \mathrm{inH}_{2} \mathrm{O}\right)$. This difference continued at post-test when brass players produced $32.5 \%$ higher MEP $\left(81.60 \pm 27.63 \mathrm{inH}_{2} \mathrm{O}\right)$ than the woodwind players (61.56 $\pm 14.21 \mathrm{inH}_{2} \mathrm{O}$, Figure $2 \mathrm{~b}$ ) and was associated with a main effect for instrument type $\left(F(1,15)=5.48, p=0.033, \eta_{p}^{2}=0.27\right.$. There was no difference in EMST training response between brass and woodwind players as brass players in the training group increased MEP 
by $66.5 \%$, while, trained woodwind players increased MEP by $70.3 \%$ (3-way interaction between instrument type by group by time, $F(1,15)=0.03, p=0.87, \eta_{p}^{2}=0.002$ ).

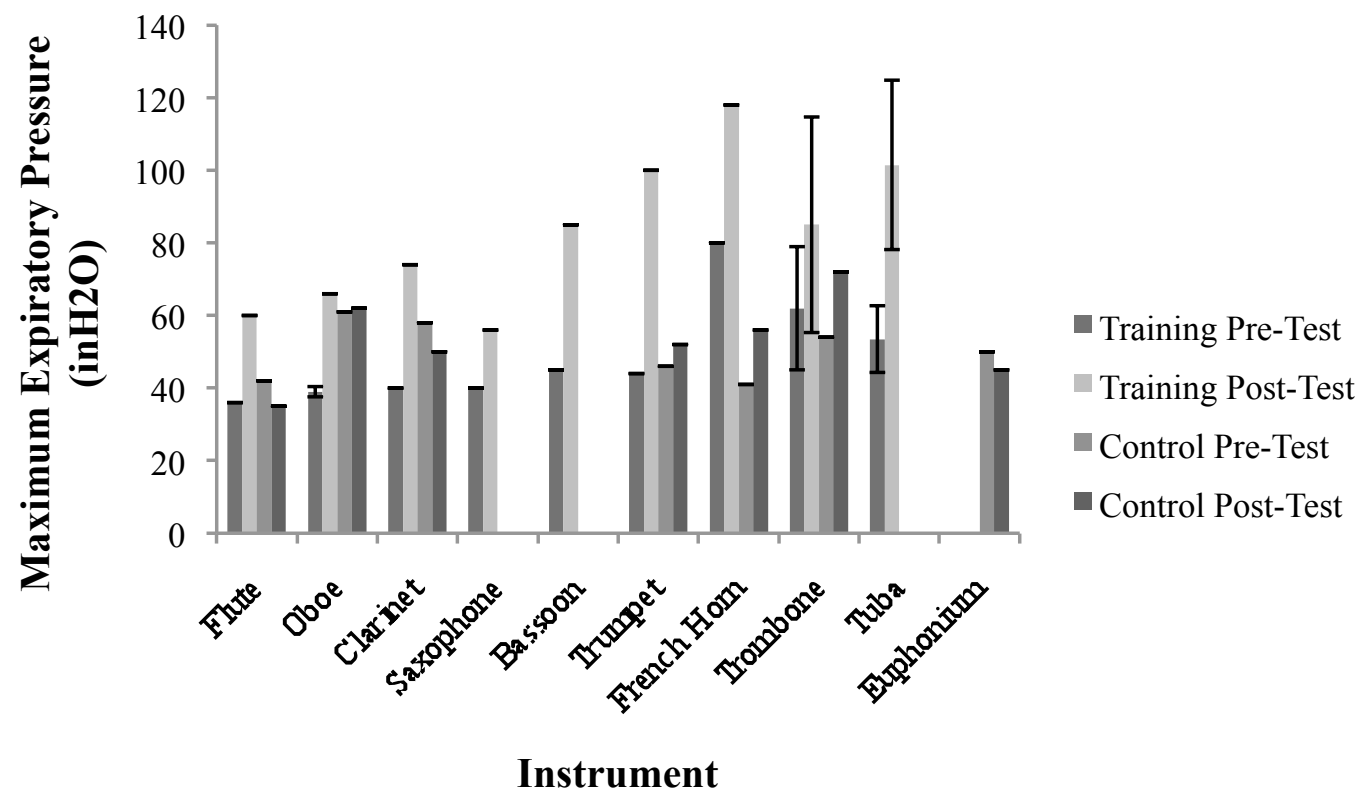

Figure 2a. Maximum Expiratory Pressure by instrument at the pre- and post-test for the control and training groups. The values have been averaged for the oboes, trombones, and tubas in the training group.

\section{MUSICAL PERFORMANCE}

Musical performance trials were completed for each of 4 tone combinations as previously described (high-pitch/high-loudness, low-pitch/high loudness, high-pitch/lowloudness and low-pitch/low loudness). Musical performance variables for the low-pitch trials were not affected by training, and results are not reported. 


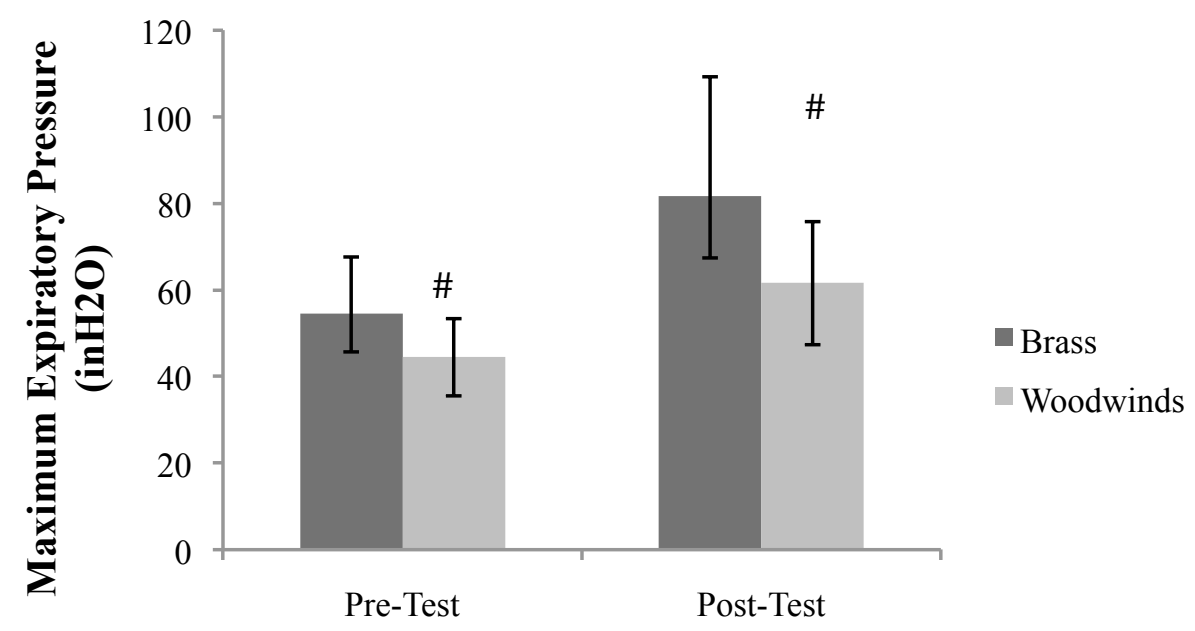

Test Session

Figure $2 b$. Maximum Expiratory Pressure for brass and woodwind instruments at the preand post-tests for combined control and training groups. \# significant difference between MEP by instrument type (main effect, $\mathrm{p}<0.05$ ).

\section{LOUDNESS}

On the high-pitch/high-loudness tone, mean loudness for the experimental group decreased (pre: $101.13 \pm 8.11 \mathrm{~dB}$; post: $95.75 \pm 7.931 \mathrm{~dB}$ ) compared to the control group (pre: $95.93 \pm 7.28$; post: $98.71 \pm 8.13 \mathrm{~dB}$ ). This resulted in a significant interaction for loudness between the training and control group over time $\left(F(1,17)=10.36, p=0.005, \eta_{p}^{2}=\right.$ 0.38 , Table 2$)$. Loudness range was not affected by training $\left(F(1,17)=0.58, p=0.46, \eta_{p}^{2}=\right.$ 0.033 , Table 2).

Similarly, for the high-pitch/low-loudness tone, the experimental group's loudness decreased (pre: $90.33 \pm 8.18 \mathrm{~dB}$; post: $83.17 \pm 8.42 \mathrm{~dB}$ ) compared to the control group (pre: $86.07 \pm 5.09$; post: $87.50 \pm 9.47 \mathrm{~dB}$ ). There was a significant interaction for loudness between the training and control group over time $\left(F(1,17)=5.23, \mathrm{p}=0.035, \eta_{p}^{2}=0.235\right)$, but training did not appear to affect loudness range $\left(F(1,17)=0.84, p=0.37, \eta_{p}^{2}=0.047\right.$, Table 2). 
Table 2.

Mean Musical Performance Data for High-Pitch Tones in the Training and Control groups at Pre and Post-test.

\begin{tabular}{|c|c|c|c|c|c|c|c|c|c|c|}
\hline Group & Loudness & $\begin{array}{c}\text { PRE Mean } \\
\text { Loudness } \\
\text { (dB) }\end{array}$ & $\begin{array}{c}\text { POST Mean } \\
\text { Loudness } \\
(\mathrm{dB})\end{array}$ & $p$ & $\begin{array}{c}\text { PRE Mean } \\
\text { Loudness } \\
\text { Range }(\mathrm{dB})\end{array}$ & $\begin{array}{l}\text { POST Mean } \\
\text { Loudness } \\
\text { Range }(\mathrm{dB})\end{array}$ & $p$ & $\begin{array}{c}\text { PRE Mean } \\
\text { Duration } \\
(\mathrm{sec})\end{array}$ & $\begin{array}{c}\text { POST Mean } \\
\text { Duration } \\
(\mathrm{sec})\end{array}$ & $p$ \\
\hline
\end{tabular}

\begin{tabular}{|c|c|c|c|c|c|c|c|c|c|c|}
\hline EMST & High & $101.13 \pm 8.11$ & $95.75 \pm 7.93$ & $0.005^{*}$ & $4.42 \pm 2.15$ & $4.33 \pm 2.39$ & 0.46 & $16.33 \pm 7.44$ & $19.65 \pm 11.12$ & 0.16 \\
\hline Control & High & $95.93 \pm 7.28$ & $98.71 \pm 8.13$ & & $5.86 \pm 2.67$ & $6.86 \pm 3.67$ & & $24.38 \pm 13.78$ & $21.85 \pm 13.57$ & \\
\hline Control & Low & $86.07 \pm 5.09$ & $87.50 \pm 9.47$ & & $5.29 \pm 1.98$ & $5.86 \pm 2.91$ & & $24.25 \pm 9.72$ & $24.94 \pm 11.58$ & \\
\hline
\end{tabular}

Note. Values are means \pm standard deviation. $p$ values indicate interaction terms from $2 \mathrm{X} 2$ group by time repeated measures ANOVA. *significant difference between groups over time. EMST = Expiratory Muscle Strength Training. 


\section{DURATION}

The training group's mean maximum duration of play on the high-pitch/highloudness tone increased by $37.15 \pm 90.05 \%$ from the pretest to the post-test (pre: $16.33 \pm$ $7.44 \mathrm{sec}$; post: $19.65 \pm 11.12 \mathrm{sec}$ ), while the control group's duration decreased slightly (pre: $24.38 \pm 13.78 \mathrm{sec}$; post: $21.85 \pm 13.57 \mathrm{sec}$ ), but the interaction was not statistically significant $\left(\mathrm{F}(1,17)=2.20, \mathrm{p}=0.16, \eta_{p}^{2}=0.115\right.$, Table 2$)$.

On the high-pitch/low-loudness tone, the mean maximum duration of play increased from $27.50 \pm 12.89 \mathrm{sec}$ at pretest to $33.56 \pm 17.27 \mathrm{sec}$ at post-test in the training group, while in the control group, the duration remained constant (pre: $24.25 \pm 9.72 \mathrm{sec}$; post: $24.94 \pm 11.58 \mathrm{sec}$ ). The interaction between the groups was not statistically significant $\left(F(1,17)=2.04, p=0.17, \quad \eta_{p}^{2}=0.107\right.$, Table 2$)$.

\section{BREATHLESSNESS}

Breathlessness was assessed on the modified Borg scale from 6 to 20 after all trials of all tones at the pretest and the post-test. There was a trend toward a main effect for time, as breathlessness scores decreased in all participants from the pretest to the post-test in both the training group (pre:8.18 \pm 0.61 ; post: $7.55 \pm 0.60$ ) and the control group (pre: 9.14 \pm .76 ; post: $\left.8.29 \pm 0.75 ; F(1,17)=3.66, p=0.074, \eta_{p}^{2}=0.186\right)$. There was no significant interaction between the training and control groups over time $(F(1,17)=0.12, p=0.761$, $\left.\eta_{p}^{2}=0.007\right)$.

\section{ENJOYMENT}

Each participant rated his or her enjoyment of the training procedure on a scale of 1-10 after each training session. There was no significant change in enjoyment over time $\left(F(1,11)=1.207, p=0.62, \eta_{p}^{2}=0.93\right)$, although there was an increasing trend from the first session to the last session (pre: $5.58 \pm 2.31$; post: $7.83 \pm 1.12$, Figure 3 ). 


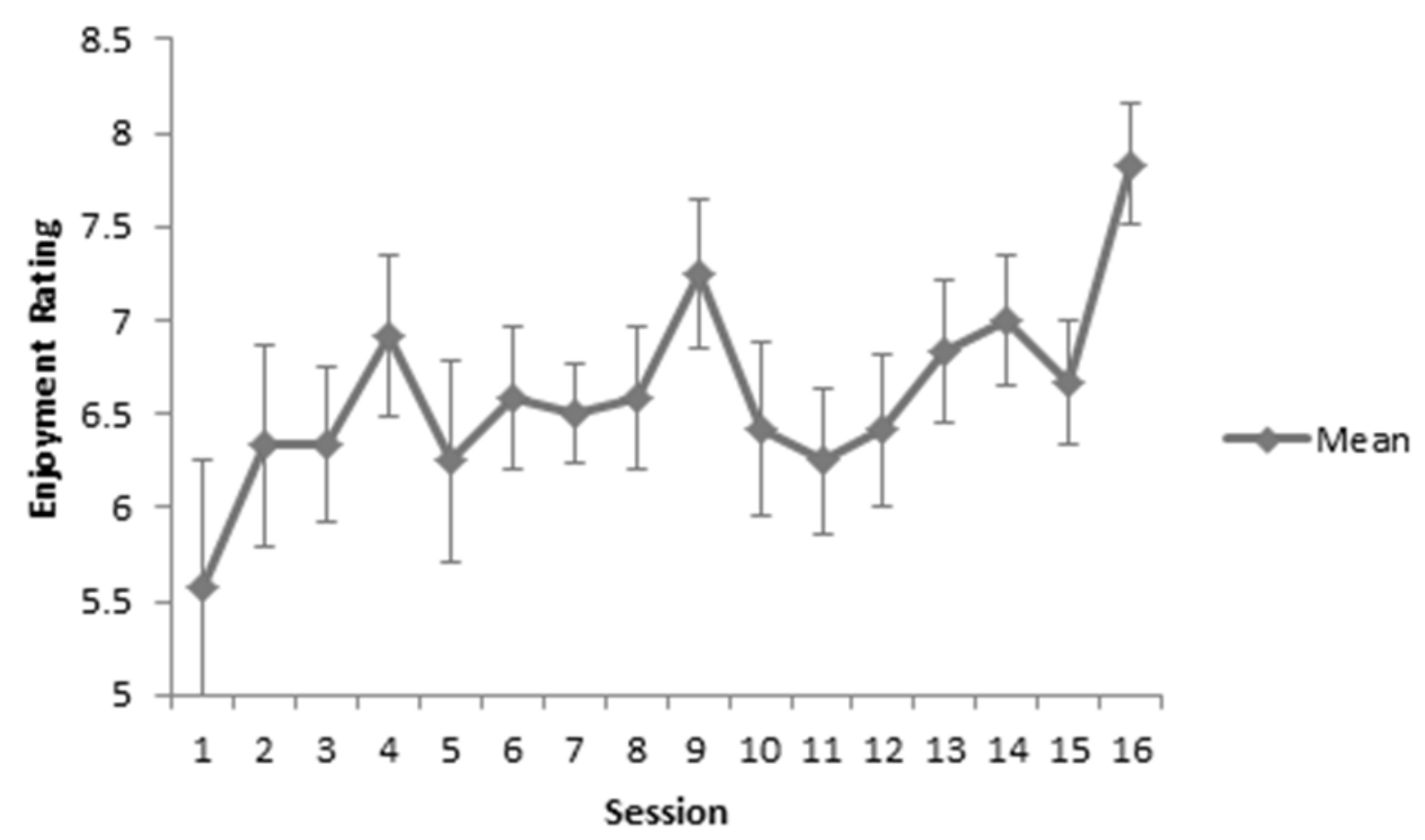

Figure 3. Mean enjoyment ratings after each training session in the experimental group

\section{DISCUSSION}

The study examined the effects of a 4-week expiratory muscle strength training (EMST) program on maximum expiratory pressure (MEP) and musical performance in collegiate wind instrumentalists. Performance was assessed using the maximum duration and the mean loudness at which each participant could play his/her highest and lowest pitches at his/her highest and lowest loudness at the pretest and the post-test. Since EMST was predicted to have the greatest effect on the duration and/or maximum loudness of the highest pitch, this tone is the primary focus of discussion.

\section{LUNG FUNCTION: MAXUMUM EXPIRATORY PRESSURE}

As expected, MEP increased significantly following 4 weeks of EMST training, but did not improve in the non-trained control group over this time period. The very high partial eta-squared value $\left(\eta_{p}^{2}\right)$ indicates that the training program was effective and accounted for $61 \%$ of the variance in MEP between training groups over time. These results support previous research (Anand et al., 2012; Sapienza et al., 2002) that reported increases in MEP of 33-51\% following various frequencies and durations of EMST in diverse populations. Our participants' MEP increased by a mean of $70.3 \pm 28.0 \%$, with a range from $28 \%$ to $127 \%$, from the pretest to the post-test over 4 weeks, demonstrating an 
even greater increase than what has been previously shown. MEP increased significantly in the training group by week 2 , and continued to increase throughout training, corroborating results shown by Baker et al. (2005), whose participants' MEP improved significantly each week of training up through week 5. Our sample was most similar to previously studied high school musicians, who showed an increase in MEP of 47-48\% over 2 weeks (Sapienza et al., 2002). The increase in MEP after training in the present study, shown in Figure 1, demonstrated that EMST can be used to greatly improve MEP in healthy collegiate wind instrumentalists, despite the fact that they may possess superior lung function prior to training (Bouhuys, 1964; Bouhuys, 1968).

When analyzed for differences between woodwind and brass instrument players, both groups showed similar improvements in MEP with training, and the brass players showed significantly greater MEP production than woodwinds at pre- and post-test. Instrument type accounted for $27 \%$ of the difference between brass and woodwind MEP. These results disagree with findings by Sapienza et al. (2002), who found no difference in pressures produced by woodwind players compared to brass instrumentalists. The difference found in the present study may be due to different pressure and flow rate requirements of each type of instrument. Bouhuys et al. (1968) showed that at the same pressure/flow rate ratios, brass instruments (trombone, bugle) generate more power than woodwind instruments (oboe, clarinet, C-flute). However, in the present study, the players gained MEP relatively equally with EMST training, as evidenced by the non-significant 3way interaction and low $\eta_{p}^{2}$ value. Moreover, the brass players maintained the greater pressures than woodwind players demonstrated at pretest at post-test as well, potentially due to long-term adaptations to the demands of their instruments as participants had 9.82 \pm 2.45 years of experience. In summary, both woodwind and brass players may benefit from EMST.

\section{LUNG FUNCTION: SPIROMETRY}

Previous research has reported that wind instrumentalists tend to have higher forced vital capacity (FVC), forced expiratory volume in one second $\left(\mathrm{FEV}_{1}\right)$, and peak expiratory flow (PEF) values than the general population (Bouhuys, 1964). Kim et al. (2005) postulated that EMST would improve peak expiratory flow during coughing, but did not test any subjects. Because PEF also aids in instrumental performance (Bouhuys, 1964; Bouhuys, 1968; Sagdeo \& Khuje, 2012), we predicted that EMST training might improve $\mathrm{PEF}$, despite a lack of previous research on this relationship. However, we did not find evidence of a training effect on FVC, FEV1, or PEF values. Expiratory muscle strength training does not appear to affect these lung function measures. Interestingly, in the present study, FVC was significantly higher in brass players than woodwind players at pretest $(p=0.03)$. This difference did not result in a significant main effect for instrument type when included in a three way 2 X2X2 (instrument type by group by time) repeated 
measures ANOVA $(F(1,15)=3.30, p=0.089)$, although $\eta_{p}^{2}$ was quite large at 0.18 . Years of playing brass instruments may have led to higher FVC in this population; however, this observation warrants further investigation.

FVC decreased significantly in both the training and control groups from pre- to post-test. However, since the decrease occurred in both groups, it is unlikely to be associated with training, and may have been due to environmental factors (Donaldson, Seemungal, Jeffries \& Wedzicha, 1991).

\section{MUSICAL PERFORMANCE}

To our knowledge, no previous research has evaluated musical performance changes in response to EMST and the resultant increased MEP. In the present study, increased MEP following EMST was not associated with significant improvements in musical performance as measured by maximal or minimal loudness or duration of play of the highest or lowest possible tone. However, following training, the average duration of play of the highest tone at maximal loudness increased by $37.2 \pm 90.0 \%$, or approximately 3 seconds, indicating a substantial practical playing advantage. Although the duration of play in the two groups was not significantly different, the $\eta_{p}^{2}$ was moderate (0.115), indicating this may be an important area for further assessment. One of the tuba players in the training group showed the greatest percent increase in duration of play $(275.6 \%)$ after training, followed by the saxophone (108.05\%), and the French horn (93.1\%), hinting that these instruments may benefit most from EMST and should be evaluated in future studies.

The only significant musical performance change noted was an unexpected interaction regarding loudness following training. However, results showed that the training group's loudness decreased with training, while the control group's loudness increased over time. This significant decrease occurred in trials when participants were asked to play their high-pitch note both as loudly as possible and also as quietly as possible. This result could thus be labeled as a performance improvement for the trial when participants were asked to play as quietly as possible. However, this result was not observed in the low-pitch/low loudness trial (results not shown), and was unexpected following EMST, which was expected to increase the pressure produced and thus increase the loudness as well. Therefore, the unexpected decrease in loudness should not be considered a performance improvement due to training. Low loudness was assessed in an attempt to separate the loudness and duration variables and was not expected to change based on the relationship between pressure and loudness stated above.

The decreased loudness under both conditions (high pitch tone / high loudness, and high-pitch tone / low loudness) may have been due to participants focusing more on playing for maximum duration rather than playing at maximum loudness during the post- 
test. During testing, verbal encouragement tended to focus more on duration and, therefore, participants may have sacrificed loudness for length of play. Future studies should ensure that encouragement is directed equally toward all outcome variables. Furthermore, testing only one outcome variable at a time may have produced different results. If we had attempted to keep both the tone and the loudness level constant at both pre and post-test, we may have seen an improvement in duration of play. However, maintaining both variables simultaneously would have been impractical and extremely difficult for the participants to maintain.

Because loudness was measured using a manual decibel meter, it was possible to record only the minimum and maximum decibel levels shown over the length of play. This technological limitation did not allow calculation of the duration of play at each decibel level or the percentage of the total duration spent at each decibel level. However, loudness range was also calculated for each trial, with most participants maintaining tones within a $10 \mathrm{~dB}$ range. A smaller loudness range following training would indicate greater consistency, which may contribute to better overall musical performance. Results indicated no effects of EMST or increased MEP on loudness range within or between groups over the training period. This may be due to limitations in our procedures and equipment, as described above. Future research should use a decibel reader that can more accurately record how loudness changes over time.

Of course, during music performance, both loudness and duration interact to contribute to the overall quality of the performance. Although we assessed these two variables separately, we observed that in all trials, loudness decreased substantially in the last several seconds of play. This indicates that a high level of loudness cannot be consistently fully sustained until the very end of a long-duration tone. The integrality of pitch, loudness, and duration make testing these factors impossible, and their interaction may have affected our results. Not only do duration and loudness interact, but so do loudness and frequency, which together affect human pitch perception (Scharine, 2002). Because pitch and loudness are integrated in the mind, having the participants focus not only on maintaining pitch, with the visible tuner, but also on loudness and on duration may have induced too many stimuli to allow enough focus on each individual aspect of musical performance. New performance measures that account for this integration should be investigated. Again, keeping two of the variables constant (pitch, loudness, and duration of play) may have allowed for measureable changes in the third variable independently of the other two, but would have presented practical challenges for the participants

The importance of the interaction between loudness and frequency can be seen in the difference between subjective and objective loudness. Subjective loudness is more important in musical performance and perception (Yanagisawa, Matsuo, Shuntoh \& Horiuchi, 2014), so perhaps we should have asked participants how loudly they thought they were able to play before and after training. Because higher pitches require higher 
energy inputs, they usually have more intensity, or objective loudness (Scharine, 2002). Thus, to the human ear, high loudness is associated with high pitches, while low loudness is usually associated with lower pitches (Scharine, 2002). A low-pitched note must have a much greater objectively measured loudness in order to sound as loud as a high-pitched note (Drake, 1970). Additionally, humans are more sensitive to changes in loudness of high-pitched notes, so lower-pitched instruments, such as the tuba, trombone, and bassoon, must put forth more energy to create discernable differences in loudness (Drake, 1970). In the present study, the lower-range instruments had to be played with more energy in order to sound as loud as the higher-pitched instruments, as well as to make the same objective gain in loudness, measured in decibels, as the higher-pitched instruments. Thus, instrumental differences affected both loudness and loudness range.

\section{PRESSURE VARIATIONS}

The wide variation in results depending on the type of instrument was expected based on previous work with pressure variations in several different instruments (Bouhuys, 1968). Pressure production and air flow rates vary with different instruments as well as with different tones on the same instrument; for example, the oboe necessitates high pressures but low flow rates, while the clarinet, unlike other instruments, requires a higher pressure on low tones than on high tones (Bouhuys, 1964). French horn players can sustain notes for significantly longer durations than other brass instruments because they have the narrowest pipes in the brass section, which increases the resistance, decreases the amount of air used to create the same airflow rate, and thus allows them to play longer (Sehmann, 2000). This is similar to the oboists, who play against a very small reed opening with a high resistance, allowing them to sustain notes for a longer duration.

Because of the considerable variation among and within instruments, we observed a wide range of musical performance results. The tone quality of a sound affects the perception of loudness, so a bad reed or a weak embouchure can thus create a deadened tone that sounds less loud (Drake, 1970). Although we did not assess tone quality in the present study, Sehmann (2000) assessed tone quality in young brass players before and after breath management training, which included basic breathing exercises to reduce overall muscle tension and improve diaphragmatic breathing, and exhalation in various rhythms and tonguing patterns. Interestingly, the trombone players in Sehmann's study demonstrated significantly lower tone quality scores than the trumpets or French horns, indicating that many factors play into tone quality besides breathing quality, such as the type of instrument, memory, articulation, and mouth placement (Sehmann, 2000). Therefore, many other factors also affect loudness and especially the perception of loudness. Based on this knowledge, our one-dimensional assessment of loudness may not have effectively captured the intricacies of dynamic control involved in musical 
performance. More research is needed to assess possible changes in tone quality related to loudness following EMST.

\section{MOUTH PRESSURE}

According to Bouhuys et al. (1968), brass instrumentalists' mouth pressure and lip tension must increase to allow them to reach higher pitches. Although mouth pressure remains constant for a given note, pleural pressure increases as air is expired and is an important driving force for tone production (Bouhuys, 1968). High, loud notes require high mouth pressures. Musicians must regulate their pleural pressure to be higher than their mouth pressure by activating their expiratory muscles when a note requires a high mouth pressure (Bouhuys, 1964). Mouth pressure appears to be more important to brass players than to woodwind players (Bouhuys, 1964). Because of the higher mouth pressures required by brass players, they must generate even higher pleural pressures. This may explain why brass players had higher absolute MEP values before and after training than the woodwind instruments. Thus, MEP training may be more important for beginning brass players in order to more quickly increase their capacity to create the high pleural and mouth pressures they need.

\section{BREATHLESSNESS}

In the present study, breathlessness showed a non-significant decreasing trend from pretest to post-test in both groups. The large $\eta_{p}^{2}$ indicates that time accounted for $18.6 \%$ of the variation in breathlessness, so this trend was likely due to a learning effect. Breathlessness was rated after 3 trials of each of 4 notes (high and low pitched tones, each at high and low loudness); separated by 1 minute of rest, with the high-pitched/highloudness, and thus most pressure-requiring, note being played first. Breathlessness scores should have been assessed after each note, rather than at the end of all 4 notes. In a study by Sasaki et al. (2005), EMST led to a decrease in the RPE of young, healthy participants during a progressive walking treadmill test. Another study demonstrated that stronger respiratory muscles improve tolerance for exercise (Sasaki, Kurosawa, \& Kohzuki, 2005). It is possible that our results may have been more compatible with other studies if players had not had sufficient recovery time between each note before assessing breathlessness.

\section{ENJOYMENT}

Participants' enjoyment ratings remained constant or increased slightly from the beginning to the end of the training period, although this change was not significant. The positive trend suggests that the addition of EMST to regular musical training, if found in future studies to be beneficial to musical performance would be reasonable and would not discourage compliance. Enjoyment scores may have been affected by whether participants 
trained alone or with a group depending on their schedules because the group training sessions provided a pleasant social environment.

\section{LIMITATIONS}

The variety of the unique demands of each instrument may have limited the results of this study. Although we attempted to place one of each instrument in each group, this was not always possible. Depending on each instrument's resistance, musicians were able to play for different amounts of time. The tubas could only sustain their low notes for 3 to 4 seconds, while the oboes and bassoons could hold their low notes for around 30 to 40 seconds. Combining all of the different instruments to calculate overall means did not account for these instrument limitations. Future research should test the performance effects of EMST in only one type of instrument to avoid complications due to differences between individual instruments.

Our equipment also limited the accuracy of our data collection. The dB meter could not automatically record loudness at each second, so the tester only recorded the range of loudnesses each participant played. We used the mean loudness from each trial, even if participants may have stayed at one loudness level for the majority of the tone duration. The EMST device was designed for non-musician populations; therefore, the pressure threshold only went up to $150 \mathrm{mmHg}$. Several of our participants reached the maximum training level and continued training at this level for the duration of the study, which may have limited their potential improvement. This drawback has been noted previously (Baker et al., 2005). Another limitation was that we matched participants by MEP, not by performance, our primary outcome variable. Future studies should match participants on performance variables first, then by MEP. Finally, alternate forms of musical performance assessment should be considered.

\section{PARTICIPANT PERCEPTIONS}

Although EMST was not found to significantly improve measures of musical performance as defined in this study, participants commented both on the perceived benefit to their playing and on the limitations of our measurement techniques. Several participants commented positively on the training. The bassoon player said she felt that her loudness and performance strength improved during rehearsals. A tuba player mentioned that it was easier to blow up balloons, and a clarinet player felt she was experiencing so much improvement from the training that she wanted to purchase an EMST device at the end of training. Brass instrumentalists (tuba, trombone, euphonium, trumpet, French horn) commonly complained that their lips gave out before their lungs, indicating that their maximum durations did not accurately represent their expiratory 
muscles' ability to produce pressure. Similarly, the oboe players had difficulty with their reeds stopping before they ran out of air. EMST may increase strength of the orbicularis oris muscle, which holds the lips closed in young, healthy males and females (Yanagisawa, Matsuo, Shuntoh, \& Horiuchi, 2014). The muscle strength increased as EMST loading increased (Yanagisawa et al., 2014). Future research in this area may seek to assess actual and/or perceived orbicularis oris strength and its effect on players' perception of lips giving out as a function of EMST.

Some of our participants experienced negative side effects from the training. One participant had jaw pain during and after training sessions. This pain was relieved by having the participant use his hand to press against his cheeks while blowing through the training device. Another person complained that her ears popped during training. Unfortunately, we could not completely eliminate this discomfort, but the popping became less bothersome with time, and was not bothersome enough to exclude the participant from the training program.

\section{RECOMMENDATIONS AND FUTURE RESEARCH}

Based on the results of this study, we do not recommend an EMST program for all wind musicians as part of a regular practice routine to enhance musical performance because significant improvements in loudness or duration did not occur across all participants and instruments after training. Four weeks of EMST 4 times per week significantly improved our participants' MEP by an average of $70.2 \pm 28.0 \%$, but this may not be a sufficient training duration or frequency to translate into improved musical performance as measured by our performance assessments. With a longer training duration, perhaps the trends toward increased duration of play would reach significance. Additionally, a different way to measure performance that incorporates the complex, integrated aspects of musicianship should be developed to assess performance more thoroughly than we were able to do. Although this study only assessed loudness and duration of holding a single pitch, which do not comprise the full range of musical skills required by musicians to create beautiful music, these skills may be important stepping stones to more advanced musicality, especially in younger players. The abilities to sustain tones over a long period of time and to control dynamics are crucial to develop phrasing and expression over a wide range of musical pieces.

The lack of significant results may be due to the small number of each of a wide variety of instruments. Each instrument type, because of the variety of mouth pressures, airflow rates, and embouchures required, may need its own performance measure to determine a specific, individualized training and practice routine. Although greater MEP has the potential to improve musical performance, we do not yet know how to optimally measure performance across the wide variety of instruments and players. Because we also 
found differences in FVC between instrument types, future research should examine FVC and MEP differences depending on instrument type.

Future research should examine performance improvements in only one type of instrument at a time, in order to determine how EMST-induced increased MEP may support players facing different instrument requirements. Instead of training and testing many different instruments, more reliable results could be obtained by using a large population of the same type of instrument.

Another goal of future research should be to develop a better way to assess musical performance. Our results may have been compromised by the inclusion of 2 dependent variables and the physiological and psychological interdependence of the duration and the loudness. Future research should focus on the relationship between these 2 variables, and on combining them in the correct proportions to create a single measure for performance. It would also be interesting to look at mouth strength training programs to supplement EMST, tone quality assessment, and breathlessness ratings after each tone is played. Another direction for future research is to examine whether EMST improves the range of pitches that a musician can reach, especially high-pitched tones which require more pressure. Finally, future research on musical support and control is needed. These are integral components to musical performance quality and should be measured and assessed in relationship to pressure variations and EMST.

\section{ACKNOWLEDGEMENTS}

The authors would like to thank Dr. Kathleen Davenport for her financial support, which allowed us to compensate our participants, and for her encouragement and suggestions throughout the writing and revision process. We would also like to thank Dr. Paul Davenport and Dr. Christina Sapienza for their donation of the EMST trainers and the pressure gauge used in this study, as well as for their valuable input and advice about the study's background, methods, and statistical analysis.

\section{REFERENCES}

Anand, S., El-Bashiti, N., \& Sapienza, C. (2012). Effect of training frequency on maximum expiratory pressure. American Journal of Speech Language Pathology, 21, 380-386. doi: 10.1044/1058-0360(2012/11-0048).

Retrieved from http://ajslp.pubs.asha.org/article.aspx?articleid=1769725

Baker, S., Davenport, P., \& Sapienza, C. (2005). Examination of strength training and detraining effects in expiratory muscles. Journal of Speech Hearing and Language Research, 48,1325-133. doi: 10.1044/1092-4388(2005/092). Retrieved from http://jslhr.pubs.asha.org/article.aspx?articleid=1783903 
Bouhuys, A. (1964). Lung volumes and breathing patterns in wind-instrument players. Journal of Applied Physiology, 19, 967-975.

Retrieved from http://jap.physiology.org/content/19/5/967

Bouhuys, A. (1968). Pressure-flow events during wind instrument playing, Annals of the New York Academy of Sciences, 155(1), 264-275, doi:10.1111/j.17496632.1968.tb56771.x.

Retrieved from http://onlinelibrary.wiley.com/doi/10.1111/i.1749-6632.1968.tb56771.x/epdf

Donaldson, G. C., Seemungal, T., Jeffries, D. J., Wedzicha, J. A. (1991). Effect of temperature on lung function and symptoms in chronic obstructive pulmonary disease. European Respiratory Journal, 13, 844-849. doi: 10.1034/j.1399-3003.1999.13d25.x.

Retrieved from http://erj.ersjournals.com/content/13/4/844.long

Drake A. H. (1970) Acoustical research on intensity and loudness and its practical application to wind instrument performance. Journal of Band Research; 6(2):5-12.

Faske, B. E. (2013). A matter of coordination: a pedagogical study of respiration, slide placement and articulation for the student trombonist and a synthesis of these processes for improved classroom instruction. (Doctoral dissertation). Retrieved from http://acumen.lib.ua.edu/content/u0015/0000001/0001472/u0015000000100 01472.pdf

Illi, S. K., Held, U., Frank, I., Spengler, C. M. (2012). Effect of respiratory muscle training on exercise performance in healthy individuals: a systematic review and meta-analysis. Sports Medicine, 42, 707-724. doi: 10.2165/11631670-000000000-00000.

Retrieved from http://www.ncbi.nlm.nih.gov/pubmed/22765281

Kim, J., Sapienza, C. M. (2005). Implications of expiratory muscle strength training for rehabilitation of the elderly: tutorial. Journal of Rehabilitation Research and Development, 42, 211-224. doi: 10.1682/JRRD.2004.07.0077. Retrieved from http://www.rehab.research.va.gov/jour/05/42/2/Kim.html

Powers, S. K., Criswell, D. (1996). Adaptive strategies of respiratory muscles in response to endurance exercise. Medicine and Science in Sports and Exercise, 28, 1115-1122. doi: 10.1097/00005768-199609000-00006.

Retrieved from http://www.ncbi.nlm.nih.gov/pubmed/8882998 
Sagdeo, M. M., Khuje, P. D. (2012). Pulmonary functions in trained and untrained wind instrument blowers. People's Journal of Scientific Research, 5, 9-12.

Retrieved from http://www.pjsr.org/July12 pdf/3.\%20Mohan\%20Manohar\%20Sagdeo.pdf

Sapienza, C. M., Davenport, P. W., Martin, A. D. (2002). Expiratory muscle training increases pressure support in high school band students. Journal of Voice, 16, 495-501. doi: 10.1016/S0892-1997(02)00125-X.

Retrieved from http://www.ncbi.nlm.nih.gov/pubmed/12512637

Sapienza, C. M., Wheeler, K. (2006). Respiratory muscle strength training: functional outcomes versus plasticity. Seminars in Speech and Language, 27, 236-244. doi: 10.1055/s-2006-955114.

Retrieved from

https://www.thieme-connect.com/DOI/DOI?10.1055/s-2006-955114

Sasaki, M., Kurosawa, H., Kohzuki, M. (2005). Effects of inspiratory and expiratory muscle training in normal subjects. Journal of the Japanese Physical Therapy Association, 8, 29-37.doi:10.1589/jpts.26.259.

Retrieved from http://www.ncbi.nlm.nih.gov/pmc/articles/PMC4316503/

Scharine, A. A. (2002). Auditory scene analysis: the role of positive correlation of dynamic changes in intensity and frequency. (Unpublished doctoral dissertation). Arizona State University, Phoenix, AZ. (UMI Number: 3054659).

Sehmann, K. H. (2000). The effects of breath management instruction on the performance of elementary brass players, Journal of Research in Music Education, 48(2), 136-150. Retrieved from http://jrm.sagepub.com/content/48/2/136.abstract

Verges, S., Lenherr, O., Haner, A. C., Schulz, C., Spengler, C. M. (2007). Increased fatigue resistance of respiratory muscles during exercise after respiratory muscle endurance training. American Journal of Physiology Regulatory, Integrative, and Comparative Physiology, 292, 1246-1253. doi: 10.1152/ajpregu.00409.2006.

Retrieved from http://ajpregu.physiology.org/content/292/3/R1246 
Yanagisawa, Y., Matsuo, Y., Shuntoh, H., Horiuchi, N. (2014). Effect of expiratory resistive loading in expiratory muscle strength training on orbicularis oris muscle activity. Journal of Physical Therapy Science, 26, 259-261. doi:10.1589/jpts.26.259.

Retrieved from http://www.ncbi.nlm.nih.gov/pmc/articles/PMC3944301/ 